\title{
Azeitonas de mesa no Brasil: mercado, tecnologia e aspectos legais
}

\author{
Table olives in Brazil: market, technology and legal aspects
}

\author{
Leandro Pereira Cappato $^{I^{*}}$ Elisa Helena da Rocha Ferreira ${ }^{\mathrm{I}}$ \\ Amauri Rosenthal ${ }^{\text {II }}$
}

- REVISÃO BIBLIOGRÁFICA -

\section{RESUMO}

Azeitona de mesa é o produto vegetal fermentado de maior importância no mundo ocidental. Apesar de não possuir produção significativa, o Brasil está entre os dez maiores consumidores de azeitona de mesa do mundo. Para o ano safra 2013/2014 (periodo entre os dias 01 de outubro até 30 de setembro), estima-se que o país seja o segundo maior importador e o nono maior consumidor do fruto. No entanto, as características do fruto e os principais processos de elaboração de azeitonas de mesa são pouco conhecidos no Brasil. Dessa maneira, este trabalho objetiva realizar um levantamento do mercado, as principais tecnologias utilizadas e os aspectos legais associadas à produção de azeitona de mesa.

Palavras-chave: Spanish style, Greek style, Californian style, Oleuropeina.

\section{ABSTRACT}

Table olives is the greater importance fermented vegetable product in the western world. Despite not having significant production, Brazil is among the ten largest consumers of table olives in the world. For the crop year of 2013/2014 (period between 01 October to 30 September) it is estimated that the country becomes the second largest importer and the ninth-largest consumer of the fruit. However, knowledge about the fruit characteristics and the main processes of elaboration of table olives are scarce. Thus, this research aims to survey the market, main technologies and the associated legal aspects of the production of table olives.

Key words: Spanish style, Greek style, Californian style, oleuropein.

\section{INTRODUÇÃO}

A azeitona é o fruto da oliveira (Oleaeuropaea) espécie pertencente à família das oleáceas, o fruto é considerado impróprio para consumo in natura, pois apresentam um componente responsável pelo seu sabor amargo, a oleuropeína, um glicosídeo presente naturalmente nas azeitonas (ARROYO-LÓPEZ et al., 2010).

Segundo o CONSEJO OLEÍCOLA INTERNACIONAL (COI, 2004), azeitona de mesa é definida como o produto preparado a partir de frutos sadios, submetido a tratamento para eliminação do amargor natural presente no fruto e conservado mediante fermentação natural ou tratamento térmico, com ou sem conservantes, envasado com ou sem líquido de cobertura. As azeitonas são classificadas quanto ao seu estado de maturação. Assim, há azeitona verde, de cor transitória e preta.

Em geral, apresentam, em média, baixos teores de açúcares $(2,5-6,0 \%)$ e alto teor de ácidos graxos (9,0-30,0\%), valores que variam de acordo com o tipo de azeitona, o grau de maturação, sazonalidade e variedade (ARROYO-LÓPEZ et al., 2010). O processamento do fruto tem como principal objetivo a eliminação da oleuropeína. Existem diversos tipos, sendo os de maior importância conhecidos como: Californian style, Greek style e Spanish style.

'Departamento de Tecnologia de Alimentos (DTA), Universidade Federal Rural do Rio de Janeiro (UFRRJ), BR 465, Km 7, 23890-000, Seropédica, RJ, Brasil. E-mail: leandrocappato@gmail.com. *Autor para correspondência.

IIEmbrapa Agroindústria de Alimentos (CTAA), Guaratiba, RJ, Brasil. 
O Californian style consiste no enegrecimento de azeitonas através da oxidação alcalina. No Greek style, as azeitonas são processadas mediante a fermentação natural dos frutos, enquanto no Spanish style as azeitonas verdes são submetidas a um tratamento através do uso de álcali (GARRIDOFERNÁNDEZ et al., 1997).

O mercado mundial de azeitona cresce a cada ano. Estima-se que na safra de 2013/2014 a produção do fruto alcance 2,5 milhões de toneladas, um aumento correspondente a 5,8\% em relação à safra de 2011/2012. No mesmo período, o Brasil foi o segundo maior importador. A estimativa é que em 2013/2014 o país importe 109.000 toneladas do fruto, aproximadamente $4,4 \%$ de toda produção mundial estimada no período (IOOC, 2013).

Em virtude da importância do Brasil no cenário mundial de azeitonas de mesa e do desconhecimento acerca do fruto, este trabalho tem como objetivo apresentar os principais processos de produção, os aspectos legais relacionados à elaboração de azeitonas de mesa e a importância desse produto no âmbito nacional.

\section{DESENVOLVIMENTO}

Mercado de azeitonas de mesa

A produção mundial de azeitona de mesa entre os anos safra 1991/1992 até 2011/2012 aumentou cerca de $169 \%$, chegando a atingir em
2011/2012 uma produção de 2.432.500 toneladas. Nesse período, a Espanha foi o maior produtor mundial do fruto (521.500t), seguido da Turquia (400.000t) e Egito (384.500t) (IOOC, 2013).

Assim como a produção, a demanda mundial de azeitona de mesa aumenta a cada ano. Para o ano safra de 2013/14, a previsão é que o consumo aumente cerca de 4,5\%, comparado com o ano 2011/2012, chegando a atingir um total de 2.668.000t. Vale ressaltar que os três maiores produtores do fruto consistiram também nos três maiores consumidores na safra de 2011/2012. A Turquia apresentou-se como o maior consumidor (350.000t), seguido do Egito (300.000t) e da Espanha (217.900t) (IOOC, 2013).

Mercado brasileiro de azeitona de mesa

Apesar de o Brasil ser o segundo maior importador do fruto, o consumo per capita do país $\left(0,5 \mathrm{~kg} \mathrm{hab}^{-1}\right)$ ainda é baixo, quando comparado a países europeus e do mediterrâneo, como Síria $(6,3 \mathrm{~kg}$ $\left.\mathrm{hab}^{-1}\right)$, Espanha $\left(4,7 \mathrm{~kg} \mathrm{hab}^{-1}\right)$ e Turquia $\left(4,7 \mathrm{~kg} \mathrm{hab}^{-1}\right)$ (IOOC, 2013; UNSD, 2012). A figura 1 representa as importações brasileiras nos anos safra 2001/2002 a 2011/2012, de acordo com a IOOC (2013).

Segundo o Ministério de Desenvolvimento, Indústria e Comércio Exterior(MDIC, 2014), dentro do período de 2001/2002 até 2011/2012, as importações brasileiras totalizaram US\$ 876.201.723,00. Baseado no Sistema Harmonizado, a Nomenclatura Comum

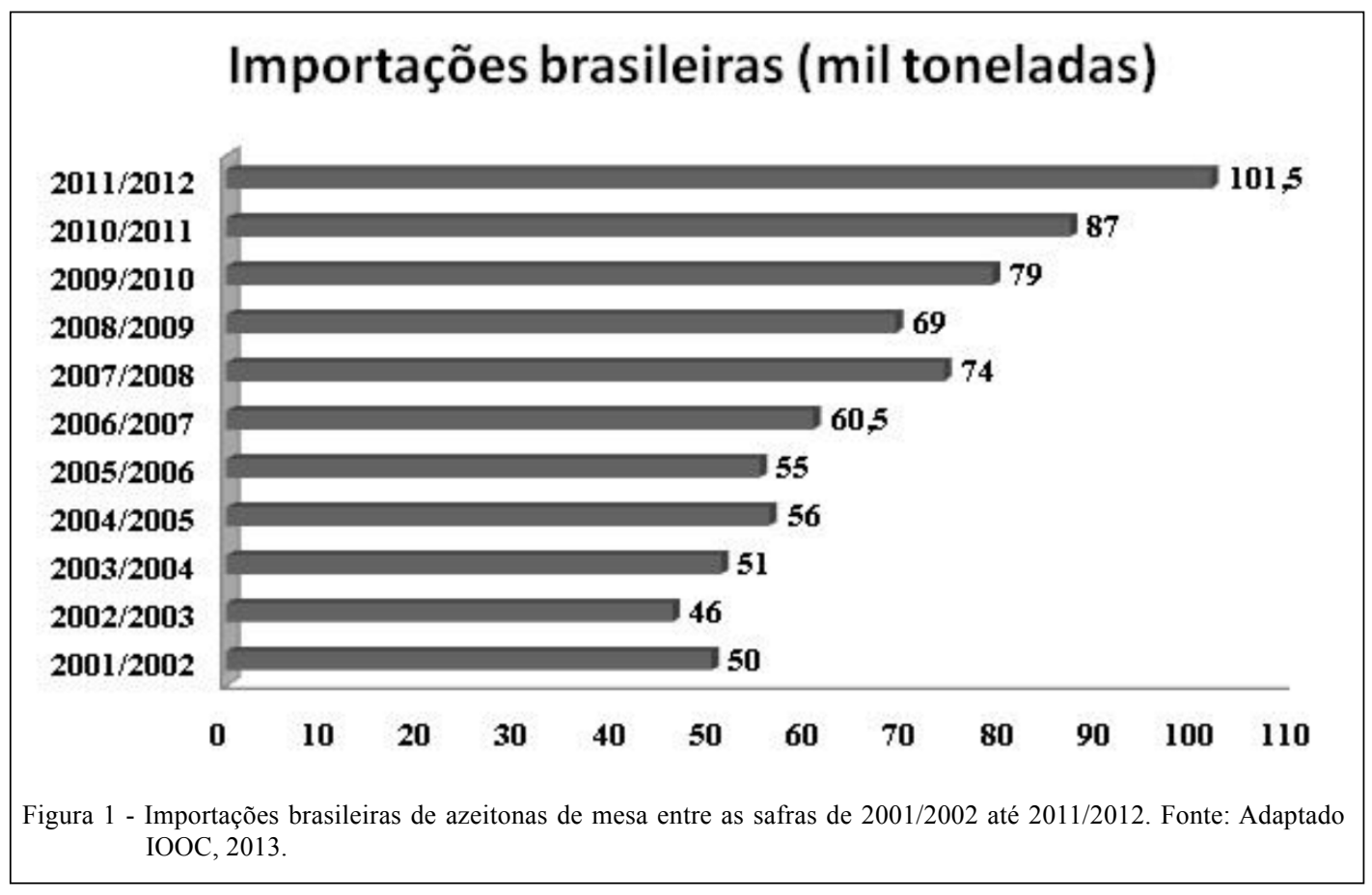

Ciência Rural, v.45, n.7, jul, 2015. 
do Mercosul (NCM) é um método para classificação e codificação de mercadorias, visando a facilitar o desenvolvimento do comércio e aprimorar a coleta de dados em âmbito nacional (MDIC, 2014). Em relação à classificação e tipos dos frutos importados, cerca de $77 \%$ das aquisições referiram-se às azeitonas preparadas em conservas, prontas para o consumo (NCM 2005.70.00), enquanto os $23 \%$ restantes corresponderam aos frutos conservados transitoriamente em barricas plásticas $(150 / 180 \mathrm{~kg})$, impróprios paraconsumonesse estado(NCM0711.20). Deste restante, $22 \%$ dos frutos corresponderam às azeitonas conservadas em água salgada (NCM $0711.20 .10)$ e $1 \%$ às azeitonas conservadas com outras substâncias destinadas a assegurar transitoriamente sua conservação (NCM 0711.20.90). As azeitonas comercializadas transitoriamente são lavadas, processadas industrialmente no Brasil e envasadas como um produto nacional. Vale ressaltar que todas as azeitonas importadas passaram por um tratamento prévio para eliminação da oleuropeína, tanto que, durante esse período, não houve importação de azeitonas frescas in natura (NCM 0709.92.00). A tabela 1 apresenta o perfil das importações brasileiras no período de 2001/2002 até 2011/2012.

Em relação aos principais fornecedores, a tabela 2 mostra os 5 maiores fornecedores do fruto no período de 2001/2002 até 2011/2012, juntos representam quase $100 \%$ da importação nacional. A Argentina é o principal fornecedor, correspondendo a 79,5\% das importações. A proximidade dos países e os aspectos tarifários, principalmente com advento do MERCOSUL, contribuíram para o fato (MDIC, 2014).
Azeitonas verdes tipo Spanish style

O processo de elaboração de azeitonas verdes tipo Spanish style, se baseia no tratamento alcalino com hidróxido de sódio $(\mathrm{NaOH})$ para eliminação do amargor natural, em que, após processos de lavagens, os frutos são imersos em salmoura e sofrem fermentação total ou parcial, podendo ser pasteurizados ou não (GARRIDOFERNÁNDEZ et al., 1997).

Os frutos são colhidos quando atingem seu tamanho máximo de desenvolvimento, ainda com coloração verde a verde-palha (ROMERO et al., 2004). A colheita pode ser realizada de duas maneiras: manualmente ou mecanicamente. $\mathrm{Na}$ colheita manual, as azeitonas são colhidas e dispostas cuidadosamente em cestas acolchoadas penduradas no pescoço, técnica conhecida como "Macaco", evitando qualquer tipo de dano. O transporte é realizado em recipientes plásticos perfurados, permitindo a aeração dos frutos, minimizando danos decorrentes das ações enzimáticas (SÁNCHEZ et al., 2006).

Tendo em vista o elevado custo da colheita manual, a colheita mecanizada está cada vez mais sendo utilizada. Até os anos noventa, essa técnica não apresentava resultados satisfatórios, em decorrência do aumento de azeitonas danificadas durante o processo. Com o avanço da tecnologia, a mecanização da colheita permitiu a obtenção de produtos finais de qualidade ainda melhores do que aqueles colhidos manualmente (SILES, 1999).

Após a colheita e o transporte até a unidade processadora, as azeitonas são selecionadas quanto ao tamanho e grau de maturação, com objetivo de melhorar a homogeneidade do tratamento alcalino

Tabela 1 - Perfil das importações brasileiras de azeitona de mesa, em relação à classificação da Nomenclatura Comum do Mercosul (NCM*), no período de 2001/2002 até 2011/2012.

\begin{tabular}{|c|c|c|c|}
\hline Classificação NCM & Quantidade (Toneladas) & $\begin{array}{l}\text { Valor total } \\
\text { US\$ FOB }\end{array}$ & $\begin{array}{l}\text { Preço Médio } \\
\text { (US\$/t) }\end{array}$ \\
\hline $\begin{array}{l}\text { NCM - 0709.92.00 Azeitonas frescas ou } \\
\text { refrigeradas }\end{array}$ & 0 & 0 & 0 \\
\hline $\begin{array}{l}\text { NCM - 0711.20.10 Azeitonas conservadas com } \\
\text { água salgada }\end{array}$ & $160.481,517$ & 133.025 .607 & 829 \\
\hline $\begin{array}{l}\text { NCM - 0711.20.20 Azeitonas com água sulfurada } \\
\text { ou adicionadas de outras substâncias }\end{array}$ & 721,594 & 794.921 & 1.102 \\
\hline $\begin{array}{l}\text { NCM - 0711.20.90 Azeitonas conservadas com } \\
\text { outras substâncias destinadas à assegurar } \\
\text { transitoriamente sua conservação }\end{array}$ & $4.523,629$ & 4.345 .951 & 961 \\
\hline NCM - 2005.70.00 Azeitonas preparadas & $563.849,405$ & 738.035 .244 & 1.309 \\
\hline Total & $729.576,145$ & 876.201 .723 & \\
\hline
\end{tabular}

*NCM - Nomenclatura Comum do Mercosul, baseado no Sistema Harmonizado (SH). Fonte: Adaptado do MDIC (2014).

Ciência Rural, v.45, n.7, jul, 2015. 
Tabela 2 - Principais fornecedores de azeitona de mesa para o Brasil no período de 2001/2002 até 2011/2012.

\begin{tabular}{lccccc}
\hline Países & $\mathrm{NCM}^{*} 0711.20 .10^{1}$ & $\mathrm{NCM} * 0711.20 .20^{2}$ & $\mathrm{NCM}^{*} 0711.20 .90^{3}$ & $\mathrm{NCM}^{*} 2005.70 .00^{4}$ & Quantidade total (t) \\
\hline Argentina & 125.272 .202 & 70.580 & 4.037 .955 & 450.310 .607 \\
Espanha & 7.222 .532 & 607.600 & 247.372 & 24.878 .852 \\
Portugal & 2.597 .457 & 13.044 & 35.711 & 6.193 .660 \\
Peru & 18.871 .742 & 22.918 & 198.353 & 74.994 .123 \\
Chile & 4.042 .772 & 0 & 0 & 6.262 .552 & 8.840 \\
Total & 158.006 .705 & 714.142 & 4.519 .391 & 562.639 .794 \\
\hline
\end{tabular}

*NCM - Nomenclatura Comum do Mercosul, baseado no Sistema Harmonizado (SH).

${ }^{1} \mathrm{NCM}$ 0711.20.10 - Azeitonas conservadas com água salgada.

${ }^{2}$ NCM 0711.20.20 - Azeitonas com água sulfurada ou adicionadas de outras substâncias.

${ }^{3} \mathrm{NCM}$ 0711.20.90 - Azeitonas conservadas com outras substâncias destinadas a assegurar transitoriamente sua conservação.

${ }^{4} \mathrm{NCM}$ 2005.70.00 - Azeitonas preparadas.

Fonte: Adaptado do MDIC (2014).

e facilitar a penetração do álcali nos frutos. Após a seleção, as azeitonas são submetidas ao tratamento alcalino, conhecido também como "cocido" ou "quemado", etapa fundamental na elaboração de azeitonas verdes. Além de eliminar a oleuropeína, o processo permite aumentar a permeabilidade da parede celular dos frutos, facilitando o processo de fermentação (ARROYO-LÓPEZ et al., 2008).

Alguns cultivares, como a 'Manzanilla', necessitam de um tempo prévio de descanso de 24 a 48h antes do "cocido", com objetivo de evitar o descascamento da pele do fruto durante o tratamento alcalino, dano conhecido como “despellejado" (REJANO et al., 2008). Porém, esse tempo de espera pode resultar na diminuição da qualidade final do fruto, devido ao desenvolvimento de processos enzimáticos responsáveis pelo aparecimento de manchas superficiais, dano conhecido como "molestado" (CARMONA et al., 2011). O "despellejado" é evitado quando se utiliza uma pré-etapa antes do "cocido", conhecido como "pré cocido", esta etapa consiste em manter os frutos imersos em hidróxido de sódio a $0,24 \%$ por aproximadamente 3 horas, podendo ser aplicado durante o transporte dos frutos, minimizando danos ocasionados no trajeto (SÁNCHEZ et al., 2006).

O tratamento é considerado finalizado quando a solução alcalina penetra cerca de $3 / 4$ de distância da pele à polpa, verificado visualmente pela utilização de solução indicadora, como a fenolftaleína. Após o término, são realizados alguns ciclos de lavagens com água por períodos de tempo variáveis, com objetivo de remover o excesso de hidróxido de sódio presente (CARMONA et al., 2011). O número de lavagens influenciará diretamente no processo de fermentação, sendo que o excesso de lavagem ocasiona perdas de componentes solúveis, como os açúcares, enquanto que o número reduzido de lavagens leva a um elevado valor de $\mathrm{pH}$ do meio, dificultando o processo fermentativo (SÁNCHEZ et al., 2001).

Ao final do ciclo de lavagens, as azeitonas são imersas em salmoura (9-12\% sal), quando sofrem fermentação láctica (ARROYO-LÓPEZ et al., 2010). Em decorrência da etapa do "cocido", o pH da salmoura no início do processo fermentativo apresenta-se bastante elevado, podendo atingir valores acima de 10 unidades (SÁNCHEZ et al., 2006). A fermentação pode ser realizada de duas maneiras: pelo processo tradicional, através da fermentação espontânea, ou pela adição de cultura starter (PERES et al., 2012).

Segundo RUIZ-BARBA \& JIMÉNEZDÍAZ (2012), no processo espontâneo, é aconselhável a redução do $\mathrm{pH}$ a valores de 6-7 unidades através da adição de ácido ou pela injeção de $\mathrm{CO}_{2}$ para evitar o desenvolvimento exagerado de Enterobacteriaceaes e Propionibacteriacea, responsáveis por deteriorações conhecidas como "olho de peixe" e "zapatera", respectivamente.

O processo fermentativo espontâneo é bem complexo, podendo ser divido em 4 etapas. Na primeira, ocorre o desenvolvimento de bactérias Gram negativas e cocos lácticos, ocasionando rápida queda no $\mathrm{pH}$ da salmoura. $\mathrm{Na}$ segunda etapa, acontece o aparecimento dos primeiros lactobacilos, quando a população cresce progressivamente à medida que o tempo passa (QUINTANA et al., 1997). A terceira fase é definida pela predominância de lactobacilos, sendo as espécies $\boldsymbol{L}$. plantarum, $\boldsymbol{L}$. pentosus e $L$. mesenteroides as mais encontradas (RUIZ-BARBA \& JIMÉNEZ-DÍAZ, 2012) e o desenvolvimento de diversos gêneros de leveduras como: Pichia, Candida e Debaryomyces (MONTAÑO et al., 2003). 
Os lactobacilos consomem os açúcares e produzem ácido láctico, reduzindo o $\mathrm{pH}$ a valores inferiores a 4,0 unidades. Já as leveduras são responsáveis pelas transformações químicas e organolépticas no produto final, como: produção de compostos aromáticos e antioxidantes (QUINTANA et al., 2005). Porém, se a redução do $\mathrm{pH}$ for ineficaz, a população de leveduras pode atingir um número maior que $10^{7} \mathrm{UFC} \mathrm{ml}^{-1}$ acarretando deteriorações, como: formação de $\mathrm{CO}_{2}$ e o amolecimento do fruto (ARROYO-LÓPEZ et al., 2008).

$\mathrm{Na}$ quarta etapa, estágio caracterizado pela conservação dos frutos em salmoura, as reações químicas relacionadas à redução do $\mathrm{pH}$ são finalizadas, devido ao consumo dos açúcares fermentáveis, resultando no aumento do $\mathrm{pH}$ (QUINTANA et al., 1997). Se as modificações químicas são brandas, não promovem alterações da estabilidade biológica, porém aumentos acima de 0,4 unidades no $\mathrm{pH}$, acarretam no desenvolvimento de alterações indesejáveis, como a "zapatera". A adição de sal e a acidificação do meio são importantes formas de evitar problemas durante essa etapa (GARRIDOFERNÁNDEZ et al., 1997). Portanto, a redução adequada do $\mathrm{pH}$ é o fator determinante para o sucesso da fermentação e a garantia de um produto seguro e de qualidade (SPYROPOULOU et al., 2001).

Devido à complexidade e à dependência exclusiva da microbiota natural do fruto para redução do $\mathrm{pH}$, o processo não espontâneo realizado através da inoculação de cultura starter é uma alternativa muito utilizada. Cepas de L. plantarium e L. pentosus, presentes no fruto, impedem o desenvolvimento de micro-organismos deteriorantes através da inibição competitiva, permitindo um rápido decréscimo do $\mathrm{pH}$, evitando qualquer tipo de deterioração microbiológica durante a fermentação (RUIZ-BARBA \& JIMÉNEZ-DÍAZ, 2012).

Em geral, ao final da fermentação, os frutos são selecionados e calibrados em relação ao tamanho, utilizando equipamentos automatizados. Os frutos são imersos em salmouras contendo altas concentrações de sal (cerca de 10\%) e baixo $\mathrm{pH}$ $(\mathrm{pH}<4,0)$, sendo estocados em barricas plásticas de aproximadamente $300 \mathrm{~kg}$, até à comercialização (SÁNCHEZ et al., 2006).

Azeitonas pretas oxidadas Californian style

Os frutos usados para elaboração das azeitonas pretas oxidadas podem ser colhidos em diferentes estágios de maturação, apresentando desde a coloração esverdeada até enegrecida (ROMERO et al., 2004). O processo de elaboração Californian style consiste em submeter os frutos a sucessivos tratamentos alcalinos, permitindo que, entre os intervalos de cada tratamento, ocorra a incorporação de oxigênio no meio, provocando a oxidação dos compostos fenólicos presentes no fruto e o seu enegrecimento. Após a oxidação, as azeitonas são envasadas, podendo ser conservadas mediante esterilização ou pasteurização. Para o processo de pasteurização, os frutos devem ser acidificados (pH<4,5) (GARCÍA et al., 1991).

Após a recepção na unidade fabril, as azeitonas são lavadas e selecionadas de acordo com o tamanho de cada fruto, pelo uso de equipamentos automatizados. Antes de serem submetidas ao tratamento alcalino, as azeitonas podem ser estocadas e preservadas em salmoura ou em água acidificada, em pH acidificado a 3,8-4,0 (SÁNCHEZ et al., 2006).

$\mathrm{O}$ processo de preservação em água acidificada, comumente utilizada nos EUA e conhecido como preservação livre de sal, consiste em estocar os frutos em água acrescida de ácido (ácido láctico e/ ou acético), sob condições anaeróbias (BRENES et al., 1998). Esse processo foi desenvolvido visando à redução do uso de sal na elaboração de azeitonas. Contudo, em virtude da ausência de sal, torna-se necessário o uso de conservantes como o benzoato de sódio, geralmente empregado em concentrações acima de $0,2 \%$, visando à inibição de micro-organismos deteriorantes, principalmente as leveduras. Além do benzoato de sódio, outro aditivo bastante utilizado é o cloreto de cálcio. Seu uso auxilia na prevenção do amolecimento na textura dos frutos preservados por longos períodos, sendo geralmente utilizadas concentrações entre $0,1 \%$ a $0,3 \%$ (p/v) (DE CASTRO et al., 2007).

$\mathrm{Na}$ Espanha, a etapa de preservação é realizada em salmoura sob condições aeróbias. Os frutos são estocados em recipientes de fermentação de fibra de vidro, imersos em salmoura a $4 \%$ a $6 \%$ (p/v). A solução salina é aerada através da passagem de ar por colunas inseridas no interior dos tanques (BRENES et al., 1998). A preservação em sistemas aerados evita o aparecimento de rugas e formação de gás, ocasionado pelo crescimento microbiano e pelo próprio metabolismo respiratório do fruto (BRENES, 2004).

Após a estocagem e preservação, os frutos são submetidos a sucessivos tratamentos utilizando solução diluída de hidróxido de sódio. Apesar da possibilidade de realização do tratamento em uma única etapa, geralmente, utiliza-se de 2 a 5 tratamentos, em concentrações entre $1,0 \%$ a $4,0 \%$ $(\mathrm{p} / \mathrm{v})$ de $\mathrm{NaOH}$. No primeiro tratamento, ocorre 
a penetração da solução alcalina pela pele do fruto, enquanto que nos tratamentos subsequentes acontece a incorporação mais profunda de $\mathrm{NaOH}$ em direção à polpa do fruto, já no último tratamento, a penetração alcança o caroço das azeitonas (SÁNCHEZ et al., 2006).

Nos intervalos entre cada tratamento, os frutos são imersos em água e expostos à presença de oxigênio através da passagem de ar por tubos inseridos no interior dos tanques. A incorporação de oxigênio promove a oxidação gradativa dos compostos fenólicos presentes no fruto, resultando no aparecimento da coloração enegrecida, característica dos frutos oxidados (MARSÍLIO et al., 2001). O uso de gluconato e/ou lactato de manganês, além de acelerar a oxidação, auxilia também na intensificação da coloração (ROMERO et al., 2001).

Com o término do tratamento alcalino, as azeitonas são lavadas várias vezes com água para promover a remoção do excesso de hidróxido de sódio presente e reduzir o $\mathrm{pH}$ a níveis inferiores a 8 unidades (MARSÍLIO et al., 2001). Em virtude da instabilidade da coloração formada e sua perda durante a vida de prateleira do produto envasado, comumente utilizam-se sais de ferro, como o gluconato ferroso ou lactato ferroso, com o intuito de auxiliar na prevenção da descoloração (GARCÍA et al., 2001). Segundo o COI, 2004, o limite máximo de uso desses estabilizantes é de $0,15 \mathrm{~g}$ de Ferro total por $\mathrm{kg}$ do fruto, ou seja, 150ppm.

Azeitonas com fermentação natural Greek style

No processo de elaboração de azeitonas fermentadas naturalmente, os frutos devem ser colhidos em seu estágio de maturação completo. Quando colhidos em estágios excessivos de maturação, os frutos perdem sua consistência, apresentando amolecimento (PANAGOU et al., 2011). O transporte dos frutos até a fábrica deve ser feito no menor tempo possível, a fim de evitar deteriorações, como o aparecimento de manchas superficiais e seu amolecimento (NYCHAS et al., 2002). Uma alternativa para evitar o amolecimento excessivo consiste em adicionar sais de cálcio a uma concentração de 0,1\% a $0,3 \%$ (SÁNCHEZ et al., 2006).

Após a chegada à unidade fabril, os frutos são imersos diretamente em salmoura sem nenhum processo prévio para a remoção do amargor natural, onde sofrem fermentação natural e espontânea. A concentração de sal pode variar entre $8 \%$ a $10 \%$ (SÁNCHEZ et al., 2006). O processo fermentativo é lento, devido ao longo período de difusão dos compostos solúveis e da lenta solubilização da oleuropeína na salmoura (HURTADO et al., 2008). A hidrólise da oleuropeína é atribuída ao $\mathrm{pH}$ ácido e à atividade da $\beta$-Glucosidase produzida pelas leveduras, principal micro-organismo presente na fermentação (PSANI \& KOTZEKIDOU, 2006). Quando todos os substratos fermentáveis, como os açúcares, se esgotam, o processo é finalizado com duração média de 8 a 12 meses (CARDOSO et al., 2010).

A fermentação das azeitonas pode ser realizada sob condições anaeróbias ou aeróbias. Além da presença ou ausência de oxigênio, outros fatores influenciam no processo, como a concentração de substratos fermentáveis, $\mathrm{pH}$, teor de sal e temperatura (SPYROPOULOU et al., 2001). Segundo TASSOU et al. (2002), teores de sal e temperatura influenciam diretamente o crescimento microbiano durante a fermentação. Foi observado que o processo fermentativo realizado a $25^{\circ} \mathrm{C}$ com $8 \%$ de sal promove a inibição do desenvolvimento de bactérias lácticas e Gram negativas, favorecendo o desenvolvimento das leveduras.

No processo fermentativo, sob ausência de oxigênio, ocorre à predominância de leveduras. Nos primeiros dias da fermentação anaeróbia, acontece o desenvolvimento das bactérias Gram negativas, como as Enterobacteriaceae (TASSOU et al., 2002). Após esse período, ocorre o desenvolvimento das leveduras, principalmente quando se utilizam elevadas concentrações de sal (8-10\%). Segundo NISIOTOU et al. (2010), a espécie de levedura dominante do processo é a Metschnikowia pulcherrima, seguida por Debaryomyces hansenii e Aureobasidium pullulans.

No processo fermentativo aeróbio, a incorporação de oxigênio tem como objetivo principal evitar o aparecimento de bolhas de gás, deterioração produzida pelo crescimento excessivo de bactérias Gram negativas (Enterobacteriaceae), conhecida também como "alambrado". O oxigênio é introduzido por uma coluna central no interior do tanque, removendo o $\mathrm{CO}_{2}$ produzido pelo metabolismo microbiano (SÁNCHEZ et al., 2006).

Após a fermentação, as azeitonas são acondicionadas em salmoura, contendo altas concentrações de sal (cerca de 10\%) e $\mathrm{pH}<4,0$, estocadas em barricas plásticas de aproximadamente $300 \mathrm{~kg}$, até à comercialização (SÁNCHEZ et al., 2006).

Comercialização de azeitonas de mesa

De acordo com a legislação que estabelece as normas aplicadas à comercialização de azeitonas 
de mesa (COI, 2004), as azeitonas diferem quanto sua forma de apresentação e comercialização. Em relação à forma de apresentação, as azeitonas são designadas como: azeitonas inteiras, com ou sem pedúnculo; azeitonas descaroçadas; azeitonas recheadas (pimentão, alho, amêndoa, etc.) e azeitonas fatiadas. Quanto à comercialização, as azeitonas são classificadas em relação ao calibre (número de frutos contidos em um quilograma); qualidade dos frutos (extra, categoria I e categoria II) e ao método de conservação.

Os frutos podem ser conservados mediante as características da salmoura de acondicionamento (água, sal e conservantes) ou mediante tratamento térmico de pasteurização ou esterilização. Segundo o COI (2004), o processo de pasteurização deve alcançar, no mínimo, $62,4^{\circ} \mathrm{C}$ por $15 \mathrm{~min}\left(\mathrm{~F}_{62,4^{\circ} \mathrm{C}}=15 \mathrm{~min}\right)$, sendo aplicado às azeitonas envasadas em salmoura ácida $(\mathrm{pH}<4,5)$, enquanto o processo de esterilização deve alcançar $121,1^{\circ} \mathrm{C}$ por no mínimo $15 \mathrm{~min}\left(\mathrm{~F}_{121,1^{\circ} \mathrm{C}}=15 \mathrm{~min}\right)$, sendo aplicado às azeitonas oxidadas tipo Californian style envasadas sob $\mathrm{pH}>4,5$ (COI, 2004). O valor de F corresponde ao tempo total de processo, em minutos, a uma temperatura fixa, para que se atinja a destruição do micro-organismo alvo, considerada consumada pela redução da população microbiana em 12 ciclos logarítmicos, no caso da esterilização, e 5 ciclos logarítmicos para a pasteurização (FDA, 2010).

\section{CONCLUSÃO}

Nesse cenário, o consumo de azeitona no Brasil apresenta grande importância frente ao mercado mundial, estando entre os dez maiores consumidores e sendo o segundo maior importador de azeitonas de mesa no mundo. A aplicação inadequada dos processos de preservação pode acarretar prejuízos significativos à qualidade do produto, bem como incorrer em riscos à sanidade do consumidor, em caso de processamento inadequado. O presente trabalho revisa e detalha as alternativas de processamento, mostrando ser viável a adoção de diferentes estilos de processo, de acordo com a demanda do consumidor, de forma a originar produtos com a qualidade desejada e a segurança microbiológica requerida, e que atendam à legislação existente.

\section{AGRADECIMENTOS}

À Universidade Federal Rural do Rio de Janeiro (UFRRJ), à Empresa Masgovi, à Embrapa Agroindústria de Alimentos, à Coordenação de Aperfeiçoamento de Pessoal de Nível
Superior (CAPES) e à Fundação de Amparo à Pesquisa do Estado do Rio de Janeiro (FAPERJ), pelo incentivo e apoio à pesquisa.

\section{REFERÊNCIAS}

ARROYO-LÓPEZ, F.N. et al. Role of yeasts in table olive production. Internacional Journal of Food Microbiology, v.128, p.189-196, 2008. Disponível em: <http://www.ncbi.nlm.nih.gov/ pubmed/18835502>. Acesso em: 10 fev. 2014. doi: 10.1016/j. ijfoodmicro.2008.08.018.

ARROYO-LÓPEZ, F.N. et al. Predictive microbiology and table olives. Current Research, Technology and Education Topics in Applied Microbiology and Microbial Biotechnology, v.II, n.13, p.1452-1461, 2010. Disponível em: <http://www.formatex.info/ microbiology2/1452-1461.pdf >. Acesso em: 10 fev. 2014.

BRENES, M. et al. Ripe olives storage liquids reuse during the oxidation process. Journal of Food Science, v.63, p.117121, 1998. Disponível em: <http://onlinelibrary.wiley.com/ doi/10.1111/j.1365-2621.1998.tb15689.x/pdf>. Acesso em: 07 ago. 2014. doi: 10.1111/j.1365-2621.

BRENES, M. et al. Absorption of sorbic and benzoic acids in the flesh of table olives. European Food Research and Technology, v.219, p.75-79, 2004. Disponível em: <http://link.springer.com/art icle/10.1007\%2Fs00217-004-0893-6>. Acesso em: 05 ago. 2014 doi: $10.1007 / \mathrm{s} 00217-004-0893-6$.

BRENES, M. Olive fermentation and processing: scientific and technological challenges. Journal of Food Science, v.69, n.1, p.33-34, 2004. Disponível em: <http://onlinelibrary.wiley.com/ doi/10.1111/j.1365-2621.2004.tb17875.x/pdf>. Acesso em: 05 ago. 2014. doi: 10.1111/j.1365-2621.2004.tb17875.x.

CARDOSO, S.M. et al. Naturally fermented black olives: effect on cell wall polysaccharides and on enzyme activities of Taggiasca and Conservolea varieties. LWT - Food Science and Technology, v.43, p.153-160, 2010. Disponível em: <http://www.sciencedirect. com/science/article/pii/S0023643809001613>. Acesso em: 20 fev. 2014. doi: 10.1016/j.lwt.2009.06.001.

CARMONA, S.J. et al. Proceso tradicional de aderezo de aceitunas verdes de mesa. Racionalización del "cocido". Grasas y Aceites, v.62, n.4, p.375-382, 2011. Disponível em: <http:// grasasyaceites.revistas.csic.es/index.php/grasasyaceites/article/ viewFile/1338/1336>. Acesso em: 25 fev. 2014. doi: 10.3989/ gya. 114610 .

COI (CONSELHO OLEÍCOLA INTERNACIONAL). Trade standard applying to table olives. 2004. Disponível em: $<$ http:// www.internationaloliveoil.org/estaticos/view/222-standards $>$. Acesso em: 01 fev. 2014.

DE CASTRO A. et al. Industrial implementation of black ripe olive storage under acid conditions. Journal of Food Engineering, v.80, n.4, p.1206-1212, 2007. Disponível em: <http://www. sciencedirect.com/science/article/pii/S026087740600598X >. Acesso em: 15 ago. 2014. doi: 10.1016/j.jfoodeng.2006.09.010.

FDA (FOOD AND DRUG ADMINISTRATION). Guidance for Industry Acidified Foods. U.S. Department of Health and Human Services, 2010. Disponível em: <http://www.fda. gov/downloads/Food/GuidanceRegulation/UCM227099.pdf>. Acesso em: 12 set. 2014. 
GARCÍA, P. et al. Effect of oxygen and temperature on the oxidation rate during the darkening step of ripe olive processing. Journal of Food Engineering, v.13, p.259-271, 1991. Disponível em: <http:// www.sciencedirect.com/science/article/pii/026087749190046U>. Acesso em: 05 ago. 2014. doi: 10.1016/0260-8774(91)90046-U.

GARCÍA, P. et al. Color fixation in ripe olives. Effect of the type of iron salt and other processing factors. Journal of the Science of Food and Agriculture, v.81, p.1364-1370, 2001. Disponivel em: $<$ http://onlinelibrary.wiley.com/doi/10.1002/jsfa.954/abstract $>$. Acesso em: 02 abr. 2014. doi: 10.1002/jsfa.954.

GARRIDO-FERNÁNDEZ, A. et al. Table Olives. Production and Processing. Londres: Chapman \& Hall, 1997. 479p.

HURTADO, A. et al. Microbial population dynamics during the processing of Arbequina table olives. Food Research International, v.41, p.738-744, 2008. Disponível em: <http://www.sciencedirect. com/science/article/pii/S0963996908001117>. Acesso em: 15 fev. 2014. doi: dx.doi.org/10.1016/j.foodres.2008.05.007.

IOOC (INTERNATIONAL OLIVE OIL COUNCIL). Statistic of table olive's world production, 2013. Disponível em <http:// www.internationaloliveoil.org/estaticos/view/132-world-tableolive-figures>. Acesso em: 10 fev. 2014.

MARSÍLIO, V. et al. Phenolic compounds during Californiastyle ripe olive processing. Food Chemistry, v.74, p.55-60, 2001. Disponível em: <http://www.sciencedirect.com/science/article/ pii/S0308814600003381>. Acesso em: 24 abr. 2014. doi: dx.doi. org/10.1016/S0308-8146(00)00338-1.

MDIC (MINISTÉRIO DO DESENVOLVIMENTO, INDÚSTRIA ECOMÉRCIO EXTERIOR). Sistema AliceWeb acesso à informação, 2014. Disponível em: <http://aliceweb.mdic.gov. br/>. Acesso em: 02 fev. 2014.

MONTAÑO, A. et al. Chemical profile of industrially fermented green olives of different varieties. Food Chemistry, v.82, p.297302, 2003. Disponível em: <http://www.sciencedirect.com/science/ article/pii/S0308814602005939>. Acesso em: 01 fev. 2014. doi: dx.doi.org/10.1016/S0308-8146(02)00593-9.

NISIOTOU, A.A. et al. Yeast heterogeneity during spontaneous fermentation of black Conservolea olives in different brine solutions. Journal of Applied Microbiology, v.108, p.396405, 2010. Disponível em: <http://www.ncbi.nlm.nih.gov/ pubmed/20438554>. Acesso em: 05 fev. 2014. doi: 10.1111/j.13652672.2009.04424.x.

NYCHAS, G.J.E. et al. Microbial colonization of naturally black olives during fermentation and associated biochemical activities in the cover brine. Letters in Applied Microbiology, v.34, p.173-177, 2002. Disponível em: <http://www.ncbi.nlm. nih.gov/pubmed/11874537>. Acesso em: 20 mar. 2014 . doi: 10.1046/j.1472-765x.2002.01077.x.

PANAGOU, E.Z. A study on the implications of $\mathrm{NaCl}$ reduction in the fermentation profile of Conservolea natural black olives. Food Microbiology, v.28, p.1301-1307, 2011. Disponível em: <http:// www.ncbi.nlm.nih.gov/pubmed/21839379>. Acesso em: 15 mar. 2014. doi: 10.1016/j.fm.2011.05.008.

PERES, C.M. et al. Review on fermented plant materials as carriers and sources of potentially probiotic lactic acid bacteria - With an emphasis on table olives. Trends in Food Science \& technology. v.26, p.31-42, 2012. Disponível em: <http://www.sciencedirect. com/science/article/pii/S0924224412000234>. Acesso em: 25 mar. 2014. doi: dx.doi.org/10.1016/j.tifs.2012.01.006.

PSANI, M.; KOTZEKIDOU, P. Technological characteristics of yeast strains and their potential as starter adjuncts in Greek-style black olive fermentation. World Journal of Microbiology and Biotechnology, v.22, p.13291336, 2006. Disponível em: <http://link.springer.com/ article/10.1007\%2Fs11274-006-9180-y>. Acesso em: 25 mar. 2014. doi: 10.1007/s11274-006-9180-y.

QUINTANA, M.O.D. et al. Bacterias del ácido láctico en la fermentación de aceitunas de mesa. Grasas y Aceites, v.48, p.297-311, 1997. Disponível em: <http://digital.csic.es/ handle/10261/21870>. Acesso em: 20 abr. 2014. doi: 10.3989/ gya.1997.v48.i5.806.

QUINTANA, M.O.D. et al. Evolucíon del crecimiento en salmuera a baja temperaturas y diferentes acidulantes, de leveduras aisladas de aceitunas de mesa. Grasas y aceites, v.56, n.1, p.9-15, 2005. Disponível em: <http://digital.csic.es/handle/10261/2440>. Acesso em: 10 abr. 2014.

REJANO, L. et al. Nuevas tendencias en el tratamiento alcalino "cocido" de las aceitunas verdes aderezadas al estilo español o sevillano. Grasas y Aceites, v.59, p.197-204, 2008. Disponível em: <http://digital.csic.es/handle/10261/7047>. Acesso em: 05 maio 2014. doi: 10.3989/gya.2008.v59.i3.509.

ROMERO C. et al. Colour improvement in ripe olive processing by addition of manganese cations. Industrial performance. Journal of Food Engineering, v.48, p.75-81, 2001. Disponível em: <http:// www.sciencedirect.com/science/article/pii/S0260877400001515>. Acesso em: 04 ago. 2014. doi: 10.1016/S0260-8774(00)00151-5.

ROMERO, C. et al. Effect of cultivar and processing method on the contents of polyphenols in table olives. Journal of Agricultural and Food Chemistry, v.52, p.479-484, 2004. Disponível em: $<$ http://pubs.acs.org/doi/abs/10.1021/jf0305251>. Acesso em: 01 fev. 2014. doi: 10.1021/jf0305251.

RUIZ-BARBA, J.L.; JIMÉNEZ-DÍAZ, A.R. A novel Lactobacillus pentosus-paired starter culture for Spanish-style green olive fermentation. Food Microbiol. v.30, p.253-259, 2012. Disponível em: <http://www.ncbi.nlm.nih.gov/pubmed/22265309>. Acesso em: 25 fev. 2014. doi: 0.1016/j.fm.2011.11.004.

SÁNCHEZ, A.H. et al. Utilization at high $\mathrm{pH}$ of starter cultures of lactobacilli for Spanish-style green olive fermentation. Internacional Journal of Food Microbiology, v.67, p.115-122, 2001. Disponível em: <http://www.sciencedirect.com/science/ article/pii/S0168160501004342>. Acesso em: 05 abr. 2014. doi: dx.doi.org/10.1016/S0168-1605(01)00434-2.

SÁNCHEZ, A.H. et al. Trends in table olives production. Elaboration of table olives. Grasas y Aceites, v.57, p.86-94, 2006. Disponível em: < http://digital.csic.es/handle/10261/7047>. Acesso em: 10 jan. 2014. doi: 10.3989/gya.2008.v59.i3.509.

SILES, F.J.S. Las nuevas tecnologías aplicadas al sector de La aceituna manzanilla fina sevillana. Grasas y Aceites, v.50, p.131140, 1999. Disponível em: <http://grasasyaceites.revistas.csic.es/ index.php/grasasyaceites/article/viewFile/648/659>. Acesso em: 10 jan. 2014. 
SPYROPOULOU, K. et al. Survival of Escherichia coli O157:H7 during the fermentation of Spanish-style green table olives (Conservolea variety) supplemented with different carbon sources. Internacional Journal of Food Microbiology, v.66, p.3-11, 2001 Disponível em: <http://www.sciencedirect.com/science/article/ pii/S0168160500005109>. Acesso em: 25 jan. 2014. doi: dx.doi. org/10.1016/S0168-1605(00)00510-9.

TASSOU, C.C. et al. Microbiological and physicochemical changes of naturally black olives fermented at different temperatures and
$\mathrm{NaCl}$ levels in the brines. Food Microbiology, v.19, p.605-615, 2002. Disponível em: <http://www.sciencedirect.com/science/ article/pii/S0740002002904806>. Acesso em: 10 fev. 2014. doi: dx.doi.org/10.1006/fmic.2002.0480.

UNSD (UNITED NATIONS STATISTICS DIVISION). Demographic and social statistics. 2012. Disponível em: $<\mathrm{http}: /$ unstats.un.org/unsd/demographic/products/socind/population>. Acesso em: 18 mar. 2014. 